\title{
Primary lymphedema French National Diagnosis and Care Protocol (PNDS; Protocole National de Diagnostic et de Soins)
}

\author{
Stéphane Vignes ${ }^{1 *} \mathbb{0}$, Juliette Albuisson², Laurence Champion ${ }^{3}$, Joël Constans ${ }^{4}$, Valérie Tauveron ${ }^{5}$, \\ Julie Malloizel ${ }^{6}$, Isabelle Quéré ${ }^{7}$, Laura Simon ${ }^{1}$, Maria Arrault ${ }^{1}$, Patrick Trévidic ${ }^{8}$, Philippe Azria ${ }^{9}$ \\ and Annabel Maruani ${ }^{10,11}$ on behalf of French National Referral Center for Primary Lymphedema
}

\begin{abstract}
Primary lymphedema is a rare chronic pathology associated with constitutional abnormalities of the lymphatic system. The objective of this French National Diagnosis and Care Protocol (Protocole National de Diagnostic et de Soins; PNDS), based on a critical literature review and multidisciplinary expert consensus, is to provide health professionals with an explanation of the optimal management and care of patients with primary lymphedema. This PNDS, written by consultants at the French National Referral Center for Primary Lymphedema, was published in 2019 (https://hassante.fr/upload/docs/application/pdf/2019-02/pnds_lymphoedeme_primaire_final_has.pdf). Primary lymphedema can be isolated or syndromic (whose manifestations are more complex with a group of symptoms) and mainly affects the lower limbs, or, much more rarely, upper limbs or external genitalia. Women are more frequently affected than men, preferentially young. The diagnosis is clinical, associating mild or non-pitting edema and skin thickening, as confirmed by the Stemmer's sign (impossibility to pinch the skin on the dorsal side or the base of the second toe), which is pathognomonic of lymphedema. Limb lymphoscintigraphy is useful to confirm the diagnosis. Other causes of swelling or edema of the lower limbs must be ruled out, such as lipedema. The main acute lymphedema complication is cellulitis (erysipelas). Functional and psychological repercussions can be major, deteriorating the patient's quality of life. Treatment aims to prevent those complications, reduce the volume with low-stretch bandages, then stabilize it over the long term by exercises and wearing a compression garment. Patient education (or parents of a child) is essential to improve observance.
\end{abstract}

Keywords: Lymphedema, Primary, Explorations, Complications, Treatment

\section{Definition}

Primary lymphedema is the accumulation of lymph in the tissues, responsible for a partial or complete increase of limb volume, followed by tissue modifications, i.e., increased cutaneous thickness and fat deposition. These changes are triggered by stimulation of adipocytes and

\footnotetext{
*Correspondence: stephane.vignes@cognacq-jay.fr

${ }^{1}$ Department of Lymphology and Reference Center for Rare Vascular

Diseases, Cognacq-Jay Hospital, 15, rue Eugène-Millon, 75015 Paris, France

Full list of author information is available at the end of the article
}

fibroblasts in response to lymph accumulation [1]. Its origin is constitutional and not the result of an iatrogenic intervention on the lymphatic system (lymph-node excision, radiotherapy), unlike secondary lymphedema. Primary lymphedema is related to hypoplasia or aplasia (rarely hyperplasia) of the lymphatic system leading to reduction of interstitial fluid absorption. It can be isolated or a component of a more complex syndrome.

This National Protocol for Diagnosis and Care (Protocole National de Diagnostic et de Soins; PNDS) addresses primary lymphedema, included in the rare vascular

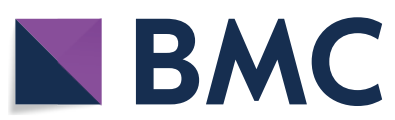

(c) The Author(s) 2021. Open Access This article is licensed under a Creative Commons Attribution 4.0 International License, which permits use, sharing, adaptation, distribution and reproduction in any medium or format, as long as you give appropriate credit to the original author(s) and the source, provide a link to the Creative Commons licence, and indicate if changes were made. The images or other third party material in this article are included in the article's Creative Commons licence, unless indicated otherwise in a credit line to the material. If material is not included in the article's Creative Commons licence and your intended use is not permitted by statutory regulation or exceeds the permitted use, you will need to obtain permission directly from the copyright holder. To view a copy of this licence, visit http://creativecommons.org/licenses/by/4.0/. The Creative Commons Public Domain Dedication waiver (http://creativeco mmons.org/publicdomain/zero/1.0/) applies to the data made available in this article, unless otherwise stated in a credit line to the data. 
disease group. This protocol focuses on the diagnosis and treatment of primary lymphedema, with an additional aim of optimizing multidisciplinary management. The PNDS was coordinated by the Primary Lymphedema Referral Center of the Referral Center for Rare Vascular Diseases and developed by a group of experts including: a member of the Lymphedema and Lymphatic Malformations Referral Center, a member of the Rare and Dermatologic Genetic Disorders Referral Center (MAGEC), physicians working in highly specialized centers, two physiotherapists, two general practitioners, a nurse, a psychologist, a plastic surgeon, a podiatrist, an orthotics specialist, a member of the patient's association and the mother of a child with primary lymphedema.

Recommendations are based on real-life experiences managing these patients in different specialized or referral centers, consensus and literature analysis. They were often extrapolated from those concerning secondary upper limb lymphedema after breast-cancer treatment. This PNDS cannot consider all specific cases: all comorbidities, hospital-care protocols, etc. It does not address the very special cases of more complex lymphatic diseases sometimes associated with lymphedema (exudative enteropathy, serous effusions). It will be updated as new data are validated. Primary lymphedema must be diagnosed by a specialist, in liaison with specialized centers and its regular follow-up coordinated with the patient's general practitioner and other health professionals.

\section{Epidemiology}

Primary lymphedema is a rare disease but its real prevalence is unknown in France [2]. It occurs mainly in women, with an $80 \%$ sex ratio according to old series, and ranges between 58 and 70\% in the most recent series [35]. Primary lymphedema is more often present at birth or appears during the first year of life for boys, whereas it occurs later in girls (9-11 years), with a global female predominance $[4,6-8]$. Primary lymphedema can be detected antenatally by ultrasound [9].

\section{Diagnosis}

Primary lymphedema is often diagnosed late ( $>10$ years between lymphedema onset and the first clinical assessment in a specialized center), because it is confused with other diagnoses (venous insufficiency, lipedema, etc.) [10-12]. It should be suspected for a patient with unexplained distal and persistent edema. The objectives are to confirm limb lymphedema, look for potential complications and evaluate the psychological and functional impacts. A diagnosis of primary lymphedema may be advanced by a family physician, pediatrician, vascular or other medical specialist (dermatologist, cardiologist, internist, geneticist, etc.) and confirmed by a trained physician in liaison with a referral or specialized center. It should also be noted that patients can come spontaneously after consulting Referral Center websites (www. maladies-vasculaires-rares.fr, www.orpha.net), patients' associations, hospital websites or social networks.

\section{Medical history \\ Adult}

- Family history (primary lymphedema, chronic venous insufficiency)

- Age at lymphedema onset

- Tropical disease (travel in a country endemic for filariasis)

- Personal history of chronic venous insufficiency

- Lymphedema reversibility or not

- Past cellulitis (number of episodes, frequency)

- Social, economic, professional, psychological, esthetic impacts

- Concomitant symptoms, such as pain, potentially suggestive of another diagnosis.

\section{Child}

Complementary information should be sought:

- pregnancy and delivery problems: intrauterine growth retardation, prematurity

- ultrasound-detected anomalies during pregnancy: anasarca and/or serous effusions, abnormal hand and/or feet volume(s) or nuchal translucency, polymalformative syndrome.

\section{Initial physical examination}

The following information should be collected: weight, height, body mass index (BMI) and for a child: weight/ height curve, cranial perimeter. Of course, signs supporting secondary lymphedema should be sought, such as adenopathies, asthenia, weight loss, anorexia, proximal topography (thigh, pubis, genitals).

Lymphedema signs:

- Inspection: increased volume of one or more limbs (Fig. 1a, b);

- Volume (or circumference) measurements, simple (tape measure), automated, comparison of the two limbs, with constant landmarks: inferior edge of the patella, anterior fold of the elbow;

- Palpation: firm skin (thickness at pinching), with mild or no pitting edema (fibrosis);

- Stemmer's sign (Fig. 2); 


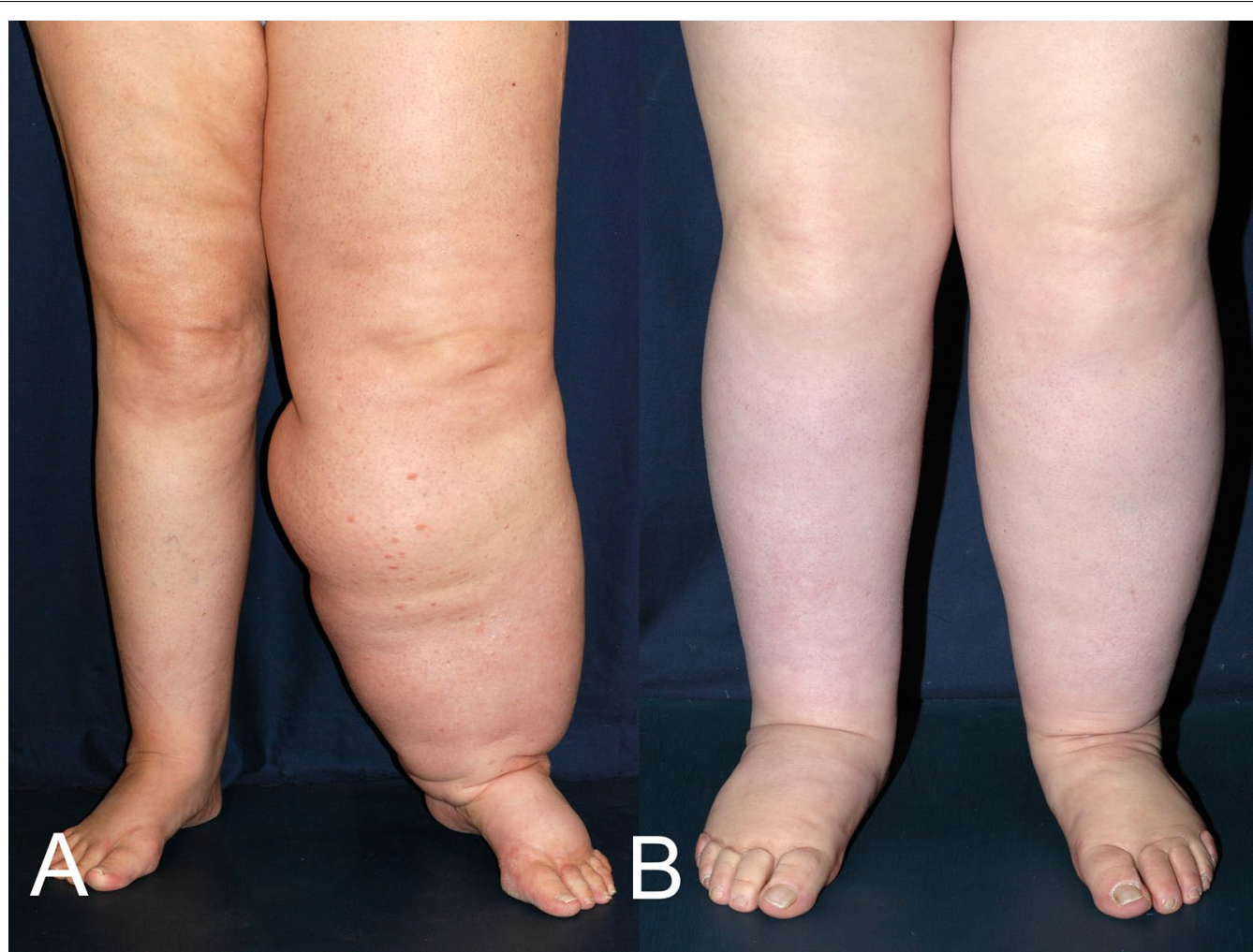

Fig. 1 Left unilateral (a), bilateral (b) primary lymphedema

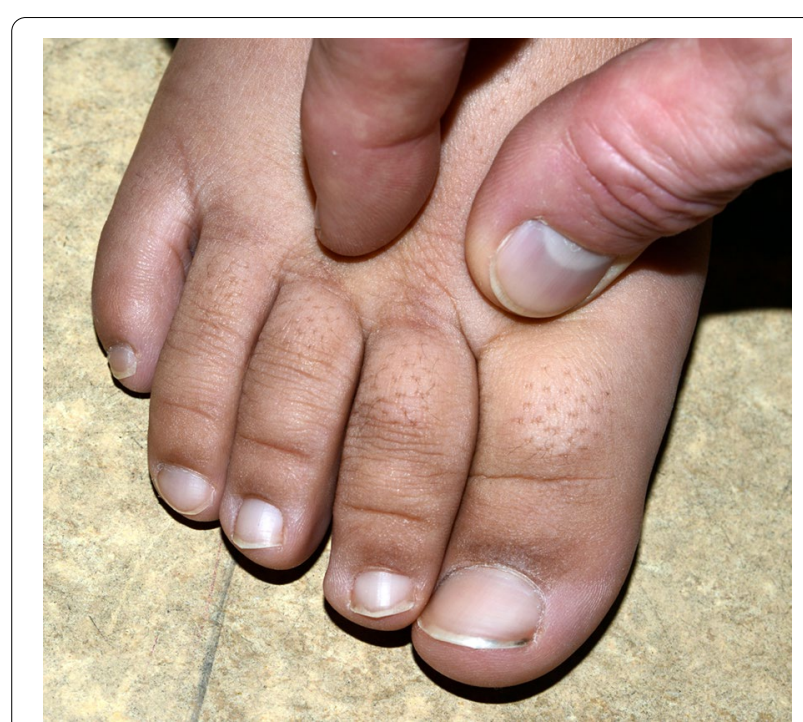

Fig. 2 Stemmer's sign: inability to pinch the skin on the base of the second toe

- Topography (uni- or bilateral, lower or upper limb, face, genitals);

- Genital lymphedema: man (increased scrotal skin thickness, testicular hydrocele, lymphedema of pubis, penis, foreskin), woman (lymphedema of major and/or minor labia, pubis). Lymphatic vesicles, possibly with lymph or chyle oozing.

Signs of lymphedema progression and complication(s):

- Cutaneous: lymphatic vesicles oozing lymph, toe papillomatosis;

- Toe-web intertrigo, ingrown nails, onychomycosis, warts;

- Nails: nail abnormalities (brachyonychia, upslanting toe nails) (Fig. 3).

Signs suggestive of a syndromic form should be sought: yellow nail(s), profuse warts, distichiasis (supernumerary row of eyelashes), vascular malformations evocative of complex vascular malformations (capillary, venous, lymphatic), hypertrophy or asymmetry of limb lengths, systemic manifestations (digestive, pulmonary, cardiac, bone), facial dysmorphia, intellectual retardation [13].

For children, specifically: clinical signs suggestive of Turner's syndrome or another polymalformative syndrome, such as Noonan's syndrome (particularly growth 


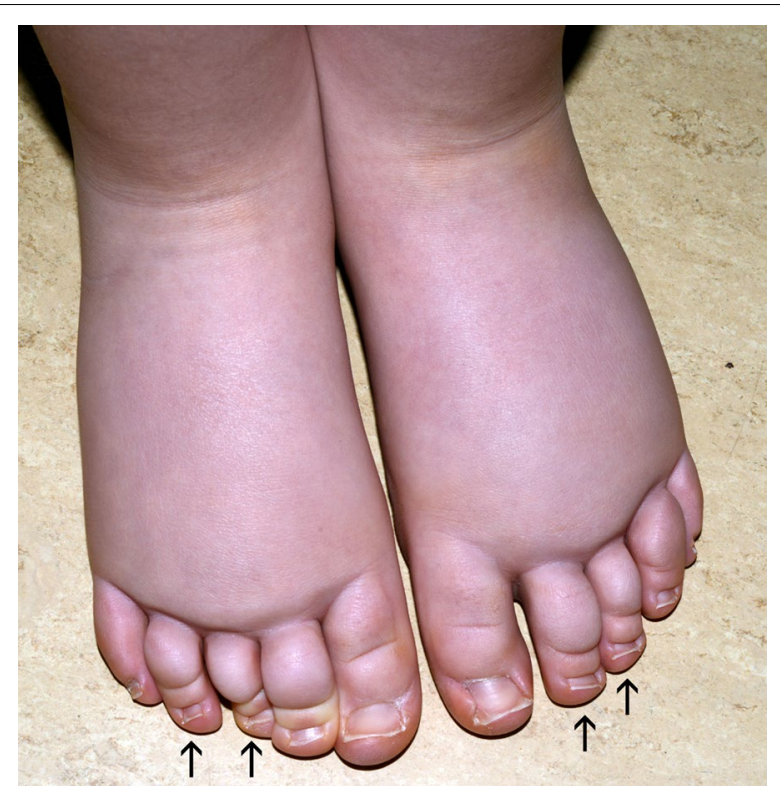

Fig. 3 Bilateral lymphedema of a 4-year-old girl with lower-limb lymphedema present at birth, upslanting nails, brachyonychia (arrow)

retardation for a girl and renal or cardiac malformations). Taking photos for follow-up is helpful.

\section{Genetic counseling}

Primary lymphedema is isolated (without other associated clinical signs) or syndromic (associated with morphological, developmental abnormalities, etc.). Isolated primary lymphedema is most often sporadic [13-22]. For a patient with isolated primary lymphedema, even hereditary, the genetic cause can only be identified individually after consultation in a referral center. On the other hand, morphological or developmental abnormality found during the physical examination (facial dysmorphism, failure to thrive, growth retardation, diverse malformations) (Table 1) should lead to a specialized genetic consultation to potentially identify the underlying syndromic disease, adapt the patient's management and offer genetic counseling to relatives. Some diseases, especially chromosomal, must be sought because their presentations may be incomplete, such as monosomy $\mathrm{X}$ (Turner's syndrome), and trisomy-21 (Down's syndrome), requiring specific care as of early childhood [23-25].

\section{Complementary investigations Explorations}

Primary lymphedema diagnosis is clinical after excluding other causes of edema. The following investigations should be obtained:
- Venous Doppler ultrasound to rule out post-thrombotic venous syndrome and look for avalvular venous insufficiency, extremely rarely associated with primary lymphedema (lymphedema-distichiasis syndrome);

- Laboratory tests: albuminemia, protein electrophoresis, proteinuria;

- Abdominal-pelvic computed-tomography (CT) scan or ultrasonography to eliminate secondary lymphedema caused by a compressive mass (increasing risk with age): when malignant disease is strongly suspected, complementary explorations may be repeated or completed with a positron-emissiontomography scan.

\section{Lymphatic system explorations}

Lymphoscintigraphy is useful to diagnose and confirm primary lymphedema [26]. It is a low radiation examination but forbidden during pregnancy and breastfeeding. Bilateral hypodermal injections are administered between the first and second toes (or fingers in rare forms of upper limb primary lymphedema). The large size of ${ }^{99 \mathrm{~m}}$ technetium radiolabeled nanocolloid, essentially albumin (rarely rhenium colloid) leads to it being entrapped only by lymphatic capillaries and then drained by lymphatic system. It enables comparative, functional and bilateral evaluation of the two upper or lower limbs: lymph-node uptake (groin, axillary), possible lymphostasis, possible dermal back flow, rerouting into the deep lymphatic system (popliteal or epitrochlear lymphnode visualization). Images are obtained usually after 40-45 min of exercises, sometimes later.

Other investigations that should not be prescribed systematically but may be useful for diagnosis or differential diagnosis [27]: limb CT scan or magnetic resonance imaging (MRI), hybrid-lymphoscintigraphy, non-enhanced lymph-MRI for more complex cases [2830], high frequency skin ultrasound [31], tissue dielectric constant, bioimpedance spectroscopy (to measure extracellular water), dual-energy X-ray absorptiometry (DEXA, to measure fat and lean masses), lymphofluoroscopy with indocyanine green to visualize lymphatics in real-time, and tissue dielectric constant are, to date, still fundamental research techniques [27, 32, 33].

For a child, neither venous ultrasonography nor laboratory analyses are ordered systematically. The physical examination remains the most important determinant, with the systematic search for clinical signs of a malformative syndrome. Lymphoscintigraphy is possible in children, usually after $7 / 8$ years of age, when they can understand their participation in the investigation. For complex malformative disease implicating the lymphatic 
Table 1 Genes implicated in isolated and syndromic lymphedema forms

\begin{tabular}{|c|c|c|c|c|c|}
\hline Syndrome & OMIM number & $\begin{array}{l}\text { Associated clinical signs (non- } \\
\text { exhaustive list) }\end{array}$ & Gene(s) implicated & Inheritance & $\begin{array}{l}\text { Estimated prevalence } \\
\text { (Orphanet 2018) }\end{array}$ \\
\hline Milroy syndrome & \#153100 & - & FLT4NEGFR3 & $A D$ & $1 / 2500$ to $1 / 10,000$ \\
\hline Milroy-like syndrome & \#615907 & - & VEGFC & $A D$ & $<1 / 100,000$ \\
\hline Meige syndrome & \#613480 & - & GJC2 & $A D$ & $<1 / 100,000$ \\
\hline Turner syndrome (X-monosomy) & & $\begin{array}{l}\text { Short stature } \\
\text { Ovarian insufficiency } \\
\text { Bone anomalies } \\
\text { Deafness } \\
\text { Cardiovascular malformations } \\
\text { Digestive malformations } \\
\text { Cardiac malformations }\end{array}$ & - & de novo & $1 / 2500$ to $1 / 10,000$ \\
\hline Down syndrome (trisomy 21) & \#190685 & $\begin{array}{l}\text { Facial dysmorphy } \\
\text { Digestive malformations } \\
\text { Skeletal malformations } \\
\text { Cardiac malformations } \\
\text { Extremities anomalies } \\
\text { Hypotony }\end{array}$ & - & $A D$ & $1 / 2500$ to $1 / 10,000$ \\
\hline Noonan syndrome types 1 and 4 & $\begin{array}{l}\# 163950 \\
\# 610733\end{array}$ & $\begin{array}{l}\text { Arterial pulmonary stenosis } \\
\text { Facial dysmorphy } \\
\text { Pterygium colli (webbed neck) } \\
\text { Learning difficulties }\end{array}$ & $\begin{array}{l}\text { PTPN11 } \\
\text { SOS1 }\end{array}$ & $A D$ & $1 / 2500$ to $1 / 10,000$ \\
\hline CM-AVM syndrome & $\# 608354$ & $\begin{array}{l}\text { Capillary malformations } \\
\text { Arteriovenous malformations }\end{array}$ & RASA1 & $\mathrm{AD} / \mathrm{mosaic}$ & $1 / 10,000$ to $1 / 100,000$ \\
\hline Lymphedema-distichiasis & $\begin{array}{l}\# 153400 \\
\# 153300\end{array}$ & $\begin{array}{l}\text { Distichiasis } \\
\text { Ungual dystrophy }\end{array}$ & FOXC2 & $A D$ & $1 / 10,000$ to $1 / 100,000$ \\
\hline Emberger's syndrome & \#614038 & $\begin{array}{l}\text { Facial dysmorphy } \\
\text { Deafness } \\
\text { Pancytopenia } \\
\text { Myelodysplasia }\end{array}$ & $\begin{array}{l}\text { MET } \\
\text { HGF } \\
\text { GATA2 }\end{array}$ & $A D$ & $1 / 100,000$ to $1 / 1,000,000$ \\
\hline Aagenaes syndrome & \#214900 & $\begin{array}{l}\text { Neonatal cholestatic liver disease } \\
\text { Hepatomegaly } \\
\text { Jaundice } \\
\text { Cirrhosis } \\
\text { Splenomegaly } \\
\text { Infantile malabsorption }\end{array}$ & $15 q$ & $A R$ & $<1 / 1,000,000$ \\
\hline Microcephaly syndrome & 152950 & $\begin{array}{l}\text { Facial dysmorphia } \\
\text { Microcephaly } \\
\text { Learning difficulties } \\
\text { Retinopathy }\end{array}$ & KIF11 & AD (de novo) & $1 / 100,000$ to $1 / 1,000,000$ \\
\hline Hennekam syndrome & \#235510 & $\begin{array}{l}\text { Intestinal lymphangiectasia } \\
\text { Exudative enteropathy } \\
\text { Learning difficulties } \\
\text { Deafness } \\
\text { Cardiac, renal, extremity malfor- } \\
\text { mations }\end{array}$ & CCBE1 & $A R$ & $<1 / 1000,000$ \\
\hline $\begin{array}{l}\text { Van Maldergem's syndrome } \\
\text { (type 2) }\end{array}$ & \# 615546 & $\begin{array}{l}\text { Facial dysmorphia } \\
\text { Learning difficulties } \\
\text { Deafness } \\
\text { Genitourinary malformations }\end{array}$ & FAT4 & $A R$ & $<1 / 1000,000$ \\
\hline Hereditary lymphedema type III & \#616843 & $\begin{array}{l}\text { Facial dysmorphia } \\
\text { Deafness } \\
\text { Learning difficulties } \\
\text { Lymphangiectasia }\end{array}$ & PIEZO1 & $A R$ & $<1 / 1,000,000$ \\
\hline
\end{tabular}


Table 1 (continued)

\begin{tabular}{|c|c|c|c|c|c|}
\hline Syndrome & OMIM number & $\begin{array}{l}\text { Associated clinical signs (non- } \\
\text { exhaustive list) }\end{array}$ & Gene(s) implicated & Inheritance & $\begin{array}{l}\text { Estimated prevalence } \\
\text { (Orphanet 2018) }\end{array}$ \\
\hline Oculodentodigital dysplasia & \#16420 & $\begin{array}{l}\text { Facial dysmorphy } \\
\text { Microcephaly } \\
\text { Psychomotor retardation } \\
\text { Neurological involvement } \\
\text { Deafness } \\
\text { Ophthalmological abnormalities } \\
\text { (microphthalmia, cataract...) } \\
\text { Dental anomalies } \\
\text { Cardiac malformations } \\
\text { Extremity anomalies }\end{array}$ & GJA1 & AD (de novo) & $<1 / 1,000,000$ \\
\hline Lymphedema-choanal atresia & \#613611 & Choanal atresia & PTPN14 & $A R$ & $<1 / 1,000000$ \\
\hline OLEDAID syndrome & \#300301 & $\begin{array}{l}\text { Ectodermic dysplasia } \\
\text { Osteopetrosis } \\
\text { Immunodeficiency }\end{array}$ & IKBKG/NEMO & $X L R$ & $<1 / 1,000,000$ \\
\hline $\begin{array}{l}\text { Hypotrichosis-lymphedema-tel- } \\
\text { angiectasia syndrome }\end{array}$ & $\begin{array}{l}\# 607823 \\
\# 137940\end{array}$ & $\begin{array}{l}\text { Facial dysmorphia } \\
\text { Hypotrichosis of the scalp and } \\
\text { face } \\
\text { Telangiectasia } \\
\text { Glomerulosclerosis }\end{array}$ & SOX18 & $\mathrm{AR} / \mathrm{AD}$ & $<1 / 1,000,000$ \\
\hline
\end{tabular}

$A D$ autosomal dominant, $A R$ autosomal recessive, OLEDAID osteopetrosis-lymphedema-ectodermal dysplasia anhidrotic with immunodeficiency, $X L R X$-linked recessive

system, MRI may be useful to assess systemic involvement and its extent.

\section{Lymphedema management}

Lymphedema management has the primary goals of reducing then stabilizing the volume, preventing complications (cellulitis) and facilitating their management, favoring patient autonomy and improving the patient's quality of life. Early and rapid treatment of primary lymphedema should be initiated as soon as it is diagnosed, to decrease the risk of developing irreversible tissue changes, e.g. fibrosis and fat deposition.

No oral treatment is available or recommended. Combining the bandaging techniques with meticulous skin care and patient education has proven efficacy [34-36]. Lymphedema management is classically divided in two distinct phases that Földi described in 1980s (Table 2). The first intensive phase, called complex (or complete) decongestive therapy aims to reduce lymphedema volume and teach the patient to take on self-management and preventive measures. The second phase seeks to obtain long-term stabilization of lymphedema volume. Recurrent intensive phases may be required to optimize lymphedema management. When lymphedema volume is moderate, an intensive phase is not always mandatory.

\section{Health professionals implicated}

After confirmation of the lymphedema diagnosis and according to each patient's needs, management requires trained health professionals from various fields: physiotherapists, nurses, pharmacists, orthopedists, orthotics specialists, therapeutic education teams, physicians, surgeons, podiatrists, dermatologists, psychologists, dieticians, nutritionists, social workers.

Regular monitoring by professionals trained in pediatric and adult lymphedema management is mandatory. Its frequency depends on lymphedema severity, evolution and complications.

Table 2 Two phases of lymphedema management

\begin{tabular}{lc}
\hline Phase 1: intensive phase (volume reduction) & Phase 2: maintenance phase (volume stabilization) \\
\hline Low-stretch bandages, $24 \mathrm{~h} / 24 \mathrm{~h}$, for 5 days to 3 weeks & Elastic compression, during the day (every day, from \\
morning to evening) & Low-stretch bandages overnight (3 nights/week) \\
Exercises while wearing the bandages & Exercises while wearing the bandages \\
Manual lymphatic drainage & Skin care
\end{tabular}




\section{Intensive phase: lymphedema-volume reduction}

Lymphedema-volume reduction ranges from 30 to $60 \%$, depending on the method used to measure lymphedema volume (perimetry, volumetry) [37, 38].

This phase includes:

- Low-stretch bandages: they include padding (foam, cotton, alveolus foam), overlaid with several layers of a low-stretch bandage (extensibility<100\%) [39]. Consensus international guidelines and the French Haute Autorité de Santé (HAS) [40] recommend only this type of bandages. Despite the lack of consensus in international recommendations or published comparative reports and the non-recommendation in the HAS 2011 and 2020 documents, some centers suggest adding an elastic or cohesive band over the lowstretch bandage [36, 37, 40].

- Exercises while wearing low-stretch bandages. These movements are not clearly codified but, by analogy with secondary upper limb lymphedema after breast cancer, must be progressive, aerobic, supervised by a trained coach and guided by patient's feedback.

- Manual lymphatic drainage (MLD). This technique has not been specifically evaluated for primary lymphedema. By extrapolating from secondary upper limb lymphedema after breast cancer, the authors of the 2015 Cochrane review could not conclude as to an MLD contribution to reducing lymphedema volume but retained a small additive effect in conjunction with low-stretch bandages on moderate lymphedema volume [41].

- Meticulous care of skin and nails (moisturizer, toeweb intertrigo treatment to detect and treat potential bacterial site(s) of entry to prevent cellulitis).

- Participation in a patient-education program authorized by the Agence Régionale de Santé (ARS; Regional Health Agency) led to the acquisition of competences: theoretical understanding of lymphedema pathophysiology; technical mastery self-bandaging and how to put on the elastic garment; to initiate early treatment of cellulitis; to adapt, cope and support autonomy and observance. Educational programs require the patient's commitment to lymphedema management, learned during the first intensive phase and applied during the maintenance phase [42].

When a child is affected, his/her parents' involvement in the care is essential. Treatment objectives are to avoid lymphedema worsening, to prevent cellulitis, to improve quality of life and to allow life to be "the most normal possible". Parents should make sure of proper skin care, weight control, and the child should continue to receive childhood immunizations as per the recommended schedule and be able to participate in physical activities and sports. By analogy with adults, lymphedema management is based on complete decongestive therapy [43-45]. MLD can be done by parents with a physiotherapist's supervision once they have learned the technique. Depending on the child's age, compressive treatment modalities must be discussed individually with the parents and child. In particular, stockings and sleeves must be changed regularly (several times a year) to accommodate the child's growth. No consensus has been reached about the use of compression for babies or infants before toddler age. Notably, some lymphedemas can regress spontaneously. Specific therapeutic education programs have been developed for children and young adults, coordinated with care or during more prolonged training sessions with on-site stays [46].

\section{Maintenance phase}

It includes the wearing a compression garment. A highpressure (class 3: 20.1-36 $\mathrm{mmHg}$; class 4:> $36 \mathrm{mmHg}$ ), custom-made, compression garment is needed to obtain the best volume stabilization. Wearing two compression garments, one on top of the other, is possible to achieve efficient high pressure [36]. Several weave types exist for compression garments: round- or flat-knitted fabric. Each has different advantages and disadvantages (thickness, rigidity, comfort, cost, etc.). In practice, flatknit compressions are mainly used for very dysmorphic limbs or with marked cutaneous folds at the ankle or leg or when it is necessary to compress the toes individually (foot/toe covers) or the fingers (glove). Superposition of compression is possible with a round-knit garment or by combining round and flat-knit materials, but difficult to obtain with flat-knit alone.

Other components of maintenance phase include bandaging less frequently than during the intensive phase, possible use of MLD, continuous meticulous skin care and weight control $[47,48]$.

\section{Other treatments, techniques under evaluation Intermittent pneumatic compression}

This technique is based on the use of sequential inflatable chambers, starting distally, with a program able to adapt the inflation/deflation durations and the pressure delivered. The device designs are different, with a variable number of chambers and programs making their comparison difficult. No high-quality study has yet been published on treatment of primary lymphedema [49].

\section{Other techniques, drugs}

Other techniques sometimes used to treat lymphedema (K-taping, acupuncture, balneotherapy, endermology, 
etc.) have not been sufficiently evaluated or have not yielded results showing reduced lymphedema volume [50]. Aqua lymphatic therapy has not been evaluated. No medical treatment has proven effective at treating lymphedema. Veinotonics are not effective. Diuretics are never indicated for lymphedema and are dangerous to use for this isolated indication. Psychological management, relaxation techniques, yoga, could be useful in some situations, even though no data are available in the literature. Nocturnal and diurnal compression systems are proposed to simplify lymphedema treatment, to improve compliance and promote autonomy. These adjustable compression wraps are currently being subjected to rigorous evaluation $[51,52]$.

\section{Organization-therapeutic indications}

Organization of intensive phase treatments depends on local availability. Treatment-outpatient or inpatientlasts for 5 days to 4 weeks, depending on the patient's personalized therapeutic objectives, lymphedema complications and locally available centers. In-hospital or outpatient treatment requires the input of a wide variety of multidisciplinary professionals (physician, physiotherapist, surgeon, nurse, pedicure/podiatrist, psychologist, therapeutic education team, dietitian, nutritionist, orthotics specialists and social workers).

All patients with primary lymphedema must have access to specialized multidisciplinary management. Most patients require intensive phase treatment followed by maintenance therapy. When the lymphedema volume is moderate, maintenance therapy alone is possible.

In the absence of dedicated studies, therapeutic approaches are not consensual and some experts prescribe treatment as soon as the diagnosis is made, others opt to adapt the indication of compression to clinical monitoring findings or even waiting until the child can walk [43]. Hospitalization is rarely necessary.

\section{Physical activity}

By analogy with the data published on secondary lymphedema (after breast or pelvic cancer), physical activities are not contraindicated [53,54]. They do not worsen lymphedema and do not induce infectious complications. No sport is restricted for adults or children and, moreover, its practice contributes to weight control. Pertinently, becoming overweight is to be prevented, especially for children, for whom prevention can be initiated early. Supervision by trained professionals, progressive and incremental increases of duration, repetition, intensity are required. Wearing a compression garment is recommended for adults and children, but not compulsory because the effort can be perceived as more difficult with compression.

\section{Complications: cellulitis (erysipelas)}

Cellulitis is an acute bacterial dermo-hypodermitis caused by $\beta$-hemolytic streptococci. Lymphedema is the main risk factor for erysipelas $[55,56]$. Clinical signs include: systemic signs (high fever of sudden onset, chills/rigors), local signs (redness, pain, heat, volume increase). Patients should be informed, within the framework of a therapeutic education program, of the potential risk of cellulitis so that they can adapt their behavior.

Cellulitis treatment lasts 7 days and is based on oral amoxicillin ( $1 \mathrm{~g} 3$ times per day for adults) or pristinamycin ( 1 g 3 times per day) or clindamycin (600 mg 3 times a day) [57]. The parenteral route is sometimes used during the first days of treatment if severity markers (arterial hypotension, shock, etc.) are present.

The criteria for hospitalization are poor clinical tolerance, severe local signs (skin detachment, cellulitis bullosa) or the existence of other associated risk factors (diabetes, elderly or very young, other comorbidities).

For children, the treatment also relies on amoxicillin $(50 \mathrm{mg} / \mathrm{kg}$ given in 3 doses for 7 days) or amoxicillin-clavulanic acid. Cellulitis occurs in children at a rate similar to that of adults with lymphedema [58]. No combination therapy (corticosteroids) is recommended; taking nonsteroidal anti-inflammatory drugs is contraindicated [57]. Fever should disappear in $48-72 \mathrm{~h}$ and local signs in less than 10 days; however, the limb volume can take weeks to return to its previous volume. During the acute phase, compressive treatment (low-stretch bandages, compression) should be maintained for as long as the patient can tolerate it.

\section{Preventive treatment}

Lymphedema treatment is essential and should help prevent cellulitis recurrences. If it does recur (2-3 cellulitis episodes per year), antibiotic prophylaxis can be prescribed, in combination with treatment of the site of entry (fungal toe-web intertrigo, fissural hyperkeratosis of the heels, onychomycosis) with benzathine-benzylpenicillin (2.4 MIU every 2-3 weeks) or oral penicillin V (1 MIU, 2-3 times a day) for a prolonged duration, not yet consensually defined $[57,59]$. Because the effect is only suspensive, the risk of recurrence exists after stopping antibiotic prophylaxis. Podiatric monitoring may be necessary.

\section{Lymphedema surgery and liposuction}

Lymphedema is a chronic disease treated with physical interventions (bandages, compression). Lymphatic-reconstruction surgery has no place today in 
the treatment of lymphedema $[60,61]$. There are three main types of surgery.

\section{Cutaneous resections}

They have the common goal of reducing or removing lymphedematous tissue or lesions complicating lymphedema, particularly lymph vesicles or papillomatous lesions. Resection of persistent excess skin after major volume reduction facilitates the bandaging and the wearing of a compression garment, which must be pursued over the long term, as surgery is merely an additional therapeutic tool. Resection (excision-plasty) is useful for male and female genital lymphedema [62]. Sometimes, circumcision can be performed alone for discomfiting foreskin lymphedema [63].

\section{Liposuction}

It removes subcutaneous lymphedematous tissue by aspiration, especially for secondary upper limb lymphedema. Post-operatively, the high-pressure compression garment must be worn continuously over the long term to maintain the surgical benefit. In practice, this technique has not been widely used, particularly because of the major constraint represented by the permanent wearing of such a garment [64].

\section{Lymphatic surgeries (reconstructive surgery)}

They are intended to "repair" the damaged lymphatic system. The methodological quality of the available studies and the occurrence of potentially serious adverse events lead us to not recommend surgery as lymphedema treatment outside clinical trials.

- Lymphovenous anastomoses are the main surgical technique used on the lymphatic system worldwide [65]. In France, this technique is used very marginally.

- Autologous lymph-node transplants may come from cervical, axillary or inguinal donor sites. Few publications of rigorous methodological quality are available, with a notable lack of objective volumetric evaluation [66]. In addition, a definite risk of inducing complications exists, particularly lymphedema at the donor site, but also lymphocele, hydrocele or local hypoesthesia [67].

For children, only genital lymphedema resection can be proposed and is subject to the opinion of a referral center. Other surgical techniques have not been evaluated [68].

\section{Main differential diagnoses \\ For adults}

Other causes (cardiac, renal or hepatic diseases) should be excluded by physical examination and clinical investigations.

Lipedema is considered a clinical entity rather than a disease and is often confused with primary lymphedema. It is defined as an abnormal accumulation of adipose tissue from hips to ankles, initially leaving the foot untouched $[69,70]$. Lipedema almost exclusively affects women, most often obese, and usually begins at puberty. The skin remains supple, painful when pinched or after physical contacts or shocks, even minor, and pitting edema is absent after a prolonged period (e.g., overnight or several hours). Signs of obesity-related venous insufficiency may be associated, as is spontaneous bruising.

Chronic venous insufficiency with edema could sometimes be mistaken for primary lymphedema but without Stemmer's sign. Venous Doppler ultrasound can help make the diagnosis. Advanced forms of chronic venous insufficiency may exhibit lymphatic overload but venous insufficiency signs are at the forefront.

\section{For children}

In newborns, it is sometimes difficult to diagnose primary lymphedema when the foot and lower leg are chubby; the diagnosis becomes clearer over the following months or years. Hamartomatous or vascular anomalies may manifest as limb hypertrophy; children should be oriented towards a referral center if lymphedema is suspected, for complementary investigations (MRI, etc.) and management [10]. For post-pubertal female adolescents, lipedema is diagnosed as for adults $[5,71]$.

\section{Follow-up}

Clinical monitoring, its frequency and its organization among general practitioner, specialist and physiotherapist depend on the lymphedema-evolution profile, which varies from one patient to another. Specialized follow-up also depends on the patient's motivation and involvement in his/her own treatment. The objectives are to stabilize lymphedema volume over the long-term, ensure the patient's treatment compliance and autonomy in coping with lymphedema, adapt the treatment to the excess volume, occurrence of complications (cellulitis, genital involvement, etc.), ensure continuity of child/adult care and take into account the psychological impact of lymphedema.

Questioning the patient during follow-up includes: episode(s) of cellulitis (number, treatment), treatment adherence according to patient's objectives and lifestyle: wearing of the compression garment (with regular 
replacement), bandages, impact on quality of life, clothing, body image, sexuality for patients with genital involvement (possible consultation with a sexologist) [72-74], psychological impact with isolation, incomprehension (use of peer groups, one-on-one discussions), aesthetic impact (consult a medical clothing designer) and functional impact: joint pain, footwear (therapeutic or orthopedic shoes).

Physical examination includes volume measurement: main criterion for adults, more difficult to grasp for children because of growth, but is nevertheless useful for unilateral lymphedema, weight, appearance of the affected limb, skin suppleness, cutaneous complications (papillomatosis, hyperkeratosis, vesicles).

\section{Role of patient-support groups}

Patient-support groups have several roles:

- to provide patients and their relatives with information in printed documents and information reviews, by organizing information meetings, with the participation of professionals, throughout France, thus participating in their education, raising public awareness and disseminating information to non-specialist professionals on lymphedema;

- to organize therapeutic education-program workshops, day meetings/sessions or short-term stays promoting lymphedema self-management (self-massage and self-monitoring) coordinated with professional caregivers;

- to create meeting spaces and telephone hotlines, allowing them to exchange experiences;

- to contact or initiate interactions with public authorities to improve patient management and quality of life;

- to represent the patients in the various health-dedicated institutions;

- to stimulate and contribute to financing for research on lymphedema and its treatment.

\begin{abstract}
Acknowledgements
The following participants contributed to the development of this protocol. Delphine Dumas (mother of a child with primary lymphedema, Montpellier), Jacques Fournier (orthotics specialists, Paris), Sandrine Jeanmaire (psychologist, Cognacq-Jay Hospital, Paris), Anna Kocher (nurse, Cognacq-Jay Hospital, Paris), Claire Leroux (physiotherapist, Cognacq-Jay Hospital, Paris), Sophie Morisot (podiatrist, Cognacq-Jay Hospital, Paris), Nicole Robert (member of a patient's association, Lymphoedème Rhône-Alpes, Lyon), Magali Souillat (physiotherapist, Toulouse), all in France.
\end{abstract}

\section{Authors' contributions}

All authors were involved in drafting the article and in revising it critically for intellectual content. All authors read and approved the final manuscript.

\section{Funding}

None.

\section{Availability of data and materials}

Data sharing not applicable to this article as no datasets were generated or analyzed during the current study.

\section{Ethics approval and consent to participate}

Not applicable.

\section{Consent for publication}

Not applicable.

\section{Competing interests}

The authors declare that they have no competing interests.

\section{Author details}

${ }_{1}^{1}$ Department of Lymphology and Reference Center for Rare Vascular Diseases, Cognacq-Jay Hospital, 15, rue Eugène-Millon, 75015 Paris, France. ${ }^{2}$ Department of Genetics, HEGP, 20, rue Leblanc, 75015 Paris, France. ${ }^{3}$ Department of Nuclear Medicine, René Huguenin-Curie Hospital, 35, rue Dailly, 92210 Saint-Cloud, France. ${ }^{4}$ Department of Vascular Medicine, Saint-André Hospital, CHU de Bordeaux, 1, rue Jean-Burguet, 33000 Bordeaux, France. ${ }^{5}$ Department of Dermatology and Reference Center for Rare Diseases and Vascular Malformations (MAGEC), CHRU Tours, 37044 Tours Cedex 9, France. ${ }^{6}$ Department of Vascular Medicine, Rangueil Hospital, 1 , avenue du Pr Jean-Poulhès, 31059 Toulouse, France. ${ }^{7}$ Department of Vascular Medicine and Reference Center for Rare Vascular Diseases, CHU Montpellier, 80, avenue Augustin-Fliche, 34090 Montpellier, France. ${ }^{8}$ Expert2expert, Paris, France. ${ }^{9}$ Department of Internal Medicine, Saint-Joseph Hospital, 185, rue Raymond-Losserand, 75014 Paris, France. ${ }^{10}$ Department of Dermatology and Reference Center for Rare Diseases and Vascular Malformations (MAGEC), CHRU Tours, 37044 Tours Cedex 9, France. ${ }^{11}$ INSERM 1246 - SPHERE, Universities of Tours and Nantes, 37000 Tours, France.

Received: 12 July 2020 Accepted: 19 December 2020

Published online: 06 January 2021

\section{References}

1. Zampell JC, Aschen S, Weitman ES, Yan A, Elhadad S, De Brot M, et al. Regulation of adipogenesis by lymphatic fluid stasis: part I. Adipogenesis, fibrosis, and inflammation. Plast Reconstr Surg. 2012;129(4):825-34. https ://doi.org/10.1097/PRS.0b013e3182450b2d.

2. Dale RF. The inheritance of primary lymphoedema. J Med Genet. 1985;22(4):274-8. https://doi.org/10.1136/jmg.22.4.274.

3. Smeltzer DM, Stickler GB, Schirger A. Primary lymphedema in children and adolescents: a follow-up study and review. Pediatrics. 1985;76(2):206-18.

4. Schook CC, Mulliken JB, Fishman SJ, Grant FD, Zurakowski D, Greene AK. Primary lymphedema: clinical features and management in 138 pediatric patients. Plast Reconstr Surg. 2011;127(6):2419-31. https://doi. org/10.1097/PRS.0b013e318213a218.

5. Blein M, Martin L, Lorette G, Vaillant L, Baulieu F, Maruani A. Lymphœè̀me primaire de l'enfant. Ann Dermatol Venereol. 2012;139(11):744-50. https://doi.org/10.1016/j.annder.2012.06.043.

6. Todd J, Craig G, Todd M, Hardy D, Young H. Audit of childhood lymphedema in the United Kingdom undertaken by members of the Children's Lymphoedema Special Interest Group. J Lymphoedema. 2014;9(2):14-9.

7. Vidal F, Arrault M, Vignes S. Paediatric primary lymphoedema: a cohort of 155 children and newborns. Br J Dermatol. 2016;175:628-31. https://doi. org/10.1111/bjd.14556.

8. Watt H, Singh-Grewal D, Wargon O, Adams S. Paediatric lymphoedema: a retrospective chart review of 86 cases J. Paediatr Child Health. 2017;53(1):38-42. https://doi.org/10.1111/jpc.13305.

9. Makhoul IR, Sujov P, Ghanem N, Bronshtein M. Prenatal diagnosis of Milroy's primary congenital lymphedema. Prenat Diagn. 2002;22(9):823-6. https://doi.org/10.1002/pd.418.

10. Schook CC, Mulliken JB, Fishman SJ, Alomari Al, Grant FD, Greene AK. Differential diagnosis of lower extremity enlargement in pediatric patients referred with a diagnosis of lymphedema. Plast Reconstr Surg. 2011;127(4):1571-81. https://doi.org/10.1097/PRS.0b013e31820a64f3. 
11. Shallwani SM, Hodgson P, Towers A. Comparisons between cancerrelated and noncancer-related lymphedema: an overview of new patients referred to a specialized hospital-based center in Canada. Lymphat Res Biol. 2017;15(1):64-9. https://doi.org/10.1089//rb.2016.0023.

12. Vignes S, Vidal F, Arrault M. Specialized consultations in a hospital-based referral center for patients suspected of having limb lymphedema: impact on diagnosis. Vasc Med. 2017;22(4):331-6. https://doi. org/10.1177/1358863X17714884.

13. Connell F, Gordon K, Brice G, Keeley V, Jeffery S, Mortimer PS, et al. The classification and diagnostic algorithm for primary lymphatic dysplasia: an update from 2010 to include molecular findings. Clin Genet. 2013;84(4):303-14. https://doi.org/10.1111/cge.12173.

14. Wassef M, Blei F, Adams D, Alomari A, Baselga E, Berenstein A, et al. ISSVA Board and Scientific Committee. Vascular anomalies classification: recommendations from the International Society for the Study of Vascular Anomalies. Pediatrics. 2015;136(1):e203-14. https://doi.org/10.1542/ peds.2014-3673.

15. Karkkainen MJ, Ferrell RE, Lawrence EC, Kimak MA, Levinson KL, McTigue MA, et al. Missense mutations interfere with VEGFR-3 signalling in primary lymphoedema. Nat Genet. 2000;25(2):153-9. https://doi. org/10.1038/75997.

16. Ghalamkarpour A, Morlot S, Raas-Rothschild A, Utkus A, Mulliken JB, Boon LM, et al. Hereditary lymphedema type I associated with VEGFR3 mutation: the first de novo case and atypical presentations. Clin Genet. 2006;70(4):330-5. https://doi.org/10.1111/j.1399-0004.2006.00687.x.

17. Ghalamkarpour A, Holnthoner W, Saharinen P, Boon LM, Mulliken JB, Alitalo K, et al. Recessive primary congenital lymphoedema caused by a VEGFR3 mutation. J Med Genet. 2009;46(6):399-404. https://doi. org/10.1136/jmg.2008.064469.

18. Gordon K, Schulte D, Brice G, Simpson MA, Roukens MG, van Impel A, et al. Mutation in vascular endothelial growth factor- $C$, a ligand for vascular endothelial growth factor receptor-3, is associated with autosomal dominant Milroy-like primary lymphedema. Circ Res. 2013;112(6):956-60. https://doi.org/10.1161/CIRCRESAHA.113.300350.

19. Fang J, Dagenais SL, Erickson RP, Arlt MF, Glynn MW, Gorski JL, et al. Mutations in FOXC2 (MFH-1), a forkhead family transcription factor, are responsible for the hereditary lymphedema-distichiasis syndrome. Am J Hum Genet. 2000;67(6):1382-8. https://doi.org/10.1086/316915.

20. Brouillard P, Boon L, Vikkula M. Genetics of lymphatic anomalies. J Clin Invest. 2014;124(3):898-904. https://doi.org/10.1172/JCI71614.

21. Michelini S, Vettori A, Maltese PE, Cardone M, Bruson A, Fiorentino A, et al. Genetic screening in a large cohort of Italian patients affected by primary lymphedema using a next generation sequencing (NGS) approach. Lymphology. 2016;49(2):57-72.

22. Michelini S, Paolacci S, Manara E, Eretta C, Mattassi R, Lee BB, et al. Genetic tests in lymphatic vascular malformations and lymphedema. J Med Genet. 2018;55(4):222-32. https://doi.org/10.1136/jmedgenet-2017105064.

23. Saenger P. Turner's syndrome. N Engl J Med. 1996;335(23):1749-54. https ://doi.org/10.1056/NEJM199612053352307.

24. Findlay CA, Donaldson MD, Watt G. Foot problems in Turner's syndrome. J Pediatr. 2001;138(5):775-7. https://doi.org/10.1067/mpd.2001.112475.

25. Rothbauer J, Driver S, Callender L. Describing lymphedema in female with Turner syndrome. Lymphology. 2015;48(3):139-52.

26. Szuba A, Shin WS, Strauss HW, Rockson S. The third circulation: radionuclide lymphoscintigraphy in the evaluation of lymphedema. J Nucl Med. 2003;44(1):43-57.

27. O'Donnell TF Jr, Rasmussen JC, Sevick-Muraca EM. New diagnostic modalities in the evaluation of lymphedema. J Vasc Surg Venous Lymphat Disord. 2017;5(2):261-73. https://doi.org/10.1016/j.jvsv.2016.10.083.

28. Duewell S, Hagspiel KD, Zuber J, von Schulthess GK, Bollinger A, Fuchs WA. Swollen lower extremity: role of MR imaging. Radiology. 1992;184(1):227-31. https://doi.org/10.1148/radiology.184.1.1609085.

29. Marotel M, Cluzan R, Ghabboun S, Pascot M, Alliot F, Lasry JL. Transaxial computer tomography of lower extremity lymphedema. Lymphology. 1998;31(4):180-5.

30. Arrivé L, Derhy S, Dahan B, El Mouhadi S, Monnier-Cholley L, Menu Y, et al. Primary lower limb lymphoedema: classification with non-contrast MR lymphography. Eur Radiol. 2018;28(1):291-300. https://doi.org/10.1007/ s00330-017-4948-z.
31. Naouri M, Samimi M, Atlan M, Perrodeau E, Vallin C, Zakine G, et al. Highresolution cutaneous ultrasonography to differentiate lipoedema from lymphoedema. Br J Dermatol. 2010;163(2):296-301. https://doi.org/10.11 11/j.1365-2133.2010.09810.x.

32. Lahtinen T, Seppälä J, Viren T, Johansson K. Experimental and analytical comparisons of tissue dielectric constant (TDC) and bioimpedance spectroscopy (BIS) in assessment of early arm lymphedema in breast cancer patients after axillary surgery and radiotherapy. Lymphat Res Biol. 2015;13(3):176-85. https://doi.org/10.1089//rb.2015.0019.

33. Gjorup CA, Hendel HW, Klausen TW, Zerahn B, Hölmich LR. Reference values for assessment of unilateral limb lymphedema with dual-energy X-ray absorptiometry. Lymphat Res Biol. 2018;16(1):75-84. https://doi. org/10.1089/Irb.2016.0064.

34. Lasinski BB, McKillip Thrift K, Squire D, Austin MK, Smith KM, Wanchai $A$, et al. A systematic review of the evidence for complete decongestive therapy in the treatment of lymphedema from 2004 to 2011. PM R. 2012:4:580-601. https://doi.org/10.1016/j.pmrj.2012.05.003.

35. Lee BB, Andrade M, Antignani PL, Boccardo F, Bunke N, Campisi C, et al. International Union of Phlebology. Diagnosis and treatment of primary lymphedema. Consensus document of the International Union of Phlebology (IUP)-2013. Int Angiol. 2013;32(6):541-74.

36. https://has-sante.fr/upload/docs/application/pdf/2010-12/fiche _de_bon_usage_-_compression_medicale_dans_les_affections_veine uses_chroniques_2010-12-16_11-04-22_128.pdf [Internet], July 12, 2020.

37. Quéré I, Presles E, Coupé M, Vignes S, Vaillant L, Eveno D, et al. POLIT Study investigators. Prospective multicentre observational study of lymphedema therapy: POLIT study. J Mal Vasc. 2014;39(4):256-63. https:// doi.org/10.1016/j.jmv.2014.05.004.

38. Vignes S, Simon L, Benoughidane B, Simon M, Fourgeaud C. Clinical and scintigraphic predictors of primary lower limb lymphedema-volume reduction during complete decongestive physical therapy. Phys Ther. 2020;100(5):766-72. https://doi.org/10.1093/ptj/pzaa012.

39. Partsch H, Clark M, Bassez S, Benigni JP, Becker F, Blazek V, et al. Measurement of lower leg compression in vivo: recommendations for the performance of measurements of interface pressure and stiffness: consensus statement. Dermatol Surg. 2006;32(2):224-32. https://doi.org/10.111 1/j.1524-4725.2006.32039.x.

40. https://has-sante.fr/upload/docs/application/pdf/2020-02/avis_bande s_allongement_long_dm_eval_244.pdf [Internet], July 12, 2020.

41. Ezzo J, Manheimer E, McNeely ML, Howell DM, Weiss R, Johansson Kl, et al. Manual lymphatic drainage for lymphedema following breast cancer treatment. Cochrane Database Syst Rev. 2015. https://doi. org/10.1002/14651858.CD003475.pub2.

42. Blaise S, Satger B, Pernod G, Richaud C, Villemur B, Carpentier PH. Impact of an educational program on the quality of life of patients with lymphedema: a preliminary evaluation. J Vasc Surg Venous Lymphat Disord. 2017;5(5):715-22.e1. https://doi.org/10.1016/j.jvsv.2017.06.004.

43. Benoughidane B, Simon L, Fourgeaud C, Vignes S. Low-stretch bandages to treat primary lower limb lymphoedema: a cohort of 48 children. $\mathrm{Br} J$ Dermatol. 2018;179(5):1203-4. https://doi.org/10.1111/bjd.16884.

44. Phillips JJ, Gordon SJ. Conservative management of lymphoedema in children: a systematic review. J Pediatr Rehabil Med. 2014;7(4):361-72. https://doi.org/10.3233/PRM-140306.

45. Damstra RJ, Mortimer P. Diagnosis and therapy in children with lymphoedema. Phlebology. 2008;23(6):276-86. https://doi.org/10.1258/phleb .2008.008010.

46. Moffatt C, Aubeeluck A, Stasi E, Macsweeney M, Mourgues F, Pourquier $\mathrm{H}$, et al. A study to explore the professional conceptualization and challenges of self-management in children and adolescents with lymphedema. Lymphat Res Biol. 2019;17(2):221-30. https://doi. org/10.1089/lrb.2018.0076.

47. Shaw C, Mortimer P, Judd PA. A randomized controlled trial of weight reduction as a treatment for breast cancer-related lymphedema. Cancer. 2007;110(8):1868-74. https://doi.org/10.1002/cncr.22994.

48. Vignes S, Arrault M, Dupuy A. Factors associated with increased breast cancer-related lymphedema volume. Acta Oncol. 2007;46(8):1138-42. https://doi.org/10.1080/02841860701403020.

49. Tran K, Argáez C. Intermittent pneumatic compression devices for the management of lymphedema: a review of clinical effectiveness and guidelines. Ottawa: Canadian Agency for Drugs and Technologies in 
Health; 2018. https://www.ncbi.nlm.nih.gov/books/NBK487690/pdf/ Bookshelf_NBK487690.pdf.

50. Rodrick JR, Poage E, Wanchai A, Stewart BR, Cormier JN, Armer JM. Complementary, alternative, and other non-complete decongestive therapy (CDT) treatment methods in the management of lymphedema: a systematic search and review. PM\&R. 2014;6(3):250-74. https://doi.org/10.1016/j. pmrj.2013.09.008.

51. Thomas $\mathrm{S}$. The use of compression wraps in the management of lymphoedema. J Lymphoedema. 2017:12(1):32-8.

52. Mestre S, Calais C, Gaillard G, Nou M, Pasqualini M, Ben Amor C, et al. Interest of an auto-adjustable nighttime compression sleeve (MOBIDERM ${ }^{\circledR}$ Autofit) in maintenance phase of upper limb lymphedema: the MARILYN pilot RCT. Support Care Cancer. 2017;25(8):2455-62. https://doi. org/10.1007/s00520-017-3652-5.

53. Baumann FT, Reike A, Reimer V, Schumann M, Hallek M, Taaffe DR, et al. Effects of physical exercise on breast cancer-related secondary lymphedema: a systematic review. Breast Cancer Res Treat. 2018;170(1):113. https://doi.org/10.1007/s10549-018-4725-y.

54. Singh B, Disipio T, Peake J, Hayes SC. Systematic review and meta-analysis of the effects of exercise for those with cancer-related lymphedema. Arch Phys Med Rehabil. 2016;97(2):302-15.e13. https://doi.org/10.1016/j. apmr.2015.09.012.

55. Dupuy A, Benchikhi H, Roujeau JC, Bernard P, Vaillant L, Chosidow O, et al. Risk factors for erysipelas of the leg (cellulitis): case-control study. BMJ. 1999;318(7198):1591-4. https://doi.org/10.1136/bmj.318.7198.1591.

56. Quirke M, Ayoub F, McCabe A, Boland F, Smith B, O'Sullivan R, et al. Risk factors for nonpurulent leg cellulitis: a systematic review and meta-analysis. Br J Dermatol. 2017;177(2):382-94. https://doi.org/10.1111/bjd.15186.

57. https://www.has-sante.fr/upload/docs/application/pdf/2019-03/fiche _de_synthese_infections_cutanees_mel.pdf. July 12, 2020.

58. Quéré I, Nagot N, Vikkula M. Incidence of cellulitis among children with primary lymphedema. N Engl J Med. 2018;378(21):2047-8. https://doi. org/10.1056/NEJMc1802399.

59. Dalal A, Eskin-Schwartz M, Mimouni D, Ray S, Days W, Hodak E, et al. Interventions for the prevention of recurrent erysipelas and cellulitis. Cochrane Database Syst Rev. 2017;6(6):CD009758. https://doi org/10.1002/14651858.CD009758.pub2.

60. Cormier JN, Rourke L, Crosby M, Chang D, Armer J. The surgical treatment of lymphedema: a systematic review of the contemporary literature (2004-2010). Ann Surg Oncol. 2012;19:642-51. https://doi.org/10.1245/ s10434-011-2017-4.

61. Schaverien MV, Moeller JA, Cleveland SD. Nonoperative treatment of lymphedema. Semin Plast Surg. 2018;32(1):17-21. https://doi. org/10.1055/s-0038-1635119.

62. Vignes S, Arrault M, Trévidic P. Surgical resection of vulva lymphoedema circumscriptum. J Plast Reconstr Aesthet Surg. 2010;63(11):1883-5. https ://doi.org/10.1016/j.bjps.2009.11.019.
63. Porter W, Dinneen M, Bunker C. Chronic penile lymphedema: a report of 6 cases. Arch Dermatol. 2001;137(8):1108-10.

64. Schaverien MV, Munnoch DA, Brorson H. Liposuction treatment of lymphedema. Semin Plast Surg. 2018;32:42-7. https://doi. org/10.1055/s-0038-1635116.

65. Boccardo F, Casabona F, De Cian F, Friedman D, Murelli F, Puglisi M, et al. Lymphatic microsurgical preventing healing approach (LYMPHA) for primary surgical prevention of breast cancer-related lymphedema: over 4 years follow-up. Microsurgery. 2014;34(6):421-4. https://doi.org/10.1002/ micr.22254.

66. Becker C, Arrive L, Saaristo A, Germain M, Fanzio P, Batista BN, et al. Surgical treatment of congenital lymphedema. Clin Plast Surg. 2012;39(4):37784. https://doi.org/10.1016/j.cps.2012.08.001.

67. Vignes S, Blanchard M, Yannoutsos A, Arrault M. Complications of autologous lymph-node transplantation for limb lymphoedema. Eur J Vasc Endovasc Surg. 2013;45(5):516-20. https://doi.org/10.1016/j. ejvs.2012.11.026.

68. Schook CC, Kulungowski AM, Greene AK, Fishman SJ. Male genital lymphedema: clinical features and management in 25 pediatric patients. J Pediatr Surg. 2014:49(11):1647-51. https://doi.org/10.1016/j.jpeds urg.2014.05.031.

69. Wold $L E$, Hines EA, Allen EV. Lipedema of the legs: a syndrome characterized by fat legs and edema. Ann Intern Med. 1951;34(5):1243-50. https:// doi.org/10.7326/0003-4819-34-5-1243.

70. Buso G, Depairon M, Tomson D, Raffoul W, Vettor R, Mazzolai L. Lipedema: a call to action! Obesity (Silver Spring). 2019;27(10):1567-76. https://doi. org/10.1002/oby.22597.

71. Vignes $S$, Vidal F, Arrault M, Boccara O. Les lymphœedèmes primaires de l'enfant. Arch Pediatr. 2017;24(8):766-76. https://doi.org/10.1016/j.arcpe d.2017.05.002.

72. Klernäs $\mathrm{P}$, Johnsson A, Horstmann V, Johansson K. Health-related quality of life in patients with lymphoedema - a cross-sectional study. Scand J Caring Sci. 2018;32(2):634-44. https://doi.org/10.1111/scs.12488.

73. Herberger K, Blome C, Heyer K, Ellis F, Münter KC, Augustin M. Quality of life in patients with primary and secondary lymphedema in the community. Wound Repair Regen. 2017;25(3):466-73. https://doi.org/10.1111/ wrr. 12529.

74. Devoogdt N, De Groef A, Hendrickx A, Damstra R, Christiaansen A, Geraerts I, et al. Lymphoedema functioning, disability and health questionnaire for lower limb lymphoedema (lymph-ICF-LL): reliability and validity. Phys Ther. 2014;94(5):705-21. https://doi.org/10.2522/ptj.20130285.

\section{Publisher's Note}

Springer Nature remains neutral with regard to jurisdictional claims in published maps and institutional affiliations.
Ready to submit your research? Choose BMC and benefit from:

- fast, convenient online submission

- thorough peer review by experienced researchers in your field

- rapid publication on acceptance

- support for research data, including large and complex data types

- gold Open Access which fosters wider collaboration and increased citations

- maximum visibility for your research: over $100 \mathrm{M}$ website views per year

At BMC, research is always in progress.

Learn more biomedcentral.com/submissions 